\title{
How to balance family with career: A man's perspective
}

\author{
Charles T. Bakhos, MD, MS, ${ }^{\mathrm{a}}$ and Mario Castillo-Sang, $\mathrm{MD}^{\mathrm{b}}$
}

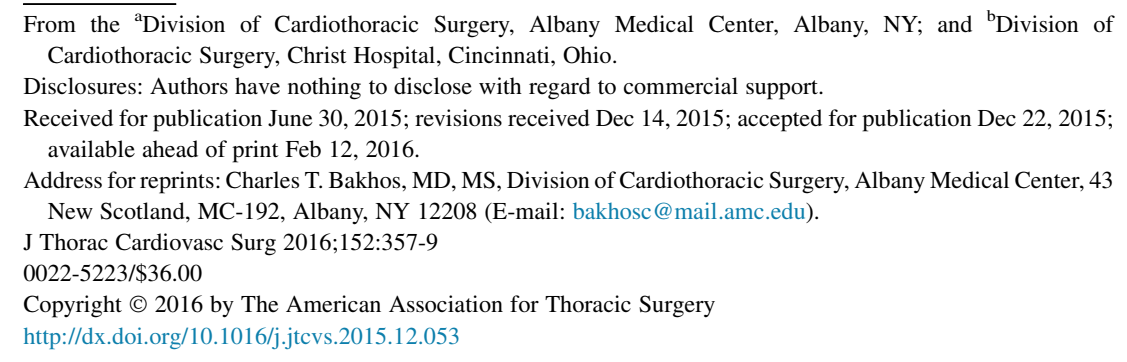

Cardiothoracic surgeons, like many other surgeons from various specialties, experience a tremendous amount of stress and are faced with life and death decisions on a routine basis. We are constantly required to perform at a high level, whether in the operating room or clinical setting, and expected to deliver excellent outcomes. Various technological advancements in the field have made coverage of all aspects of our specialty in practice more challenging, despite an arduous and demanding training.

Fulfilling administrative or research responsibilities, meeting deadlines, achieving career goals in promotion and financial peace of mind can only add to the stress and workload, and make the task of balancing work with life and family very challenging, if not elusive. These matters can be exacerbated by constant access to work e-mail, putting us at risk of becoming subjugated to work-in essence, living to work and not working to live. Operating on an aging and sicker population, as well as future prospects of public reporting of surgical outcomes and payment for performance, will undoubtedly increase the pressure facing cardiothoracic surgeons. Furthermore, with the aging of the workforce and the contraction of the resident pool, a shortage of cardiothoracic surgeons is expected in the future and can only aggravate the workload of the surgeons remaining in practice. ${ }^{1}$

This constant pressure for exemplary performance can lead to depression and burnout, as manifested by emotional exhaustion, depersonalization of, and disconnection from patients. Unfortunately, burnout not only affects health care providers, but also can have negative repercussions on their families, colleagues, and patients. Many studies have shown that burnout leads to medical errors, ineffectiveness at work, and a lower sense of gratification and career satisfaction. ${ }^{2,3}$

Young surgeons are at higher risk for burnout, as revealed by the American College of Surgeons' survey ${ }^{4}$ in 2008. This comprehensive review is still the largest to date, and reflects the challenges that face surgeons, whether in the academic or private setting, in a productivity- or salary-based model. This survey reported a staggering $40 \%$ rate of surgeons who

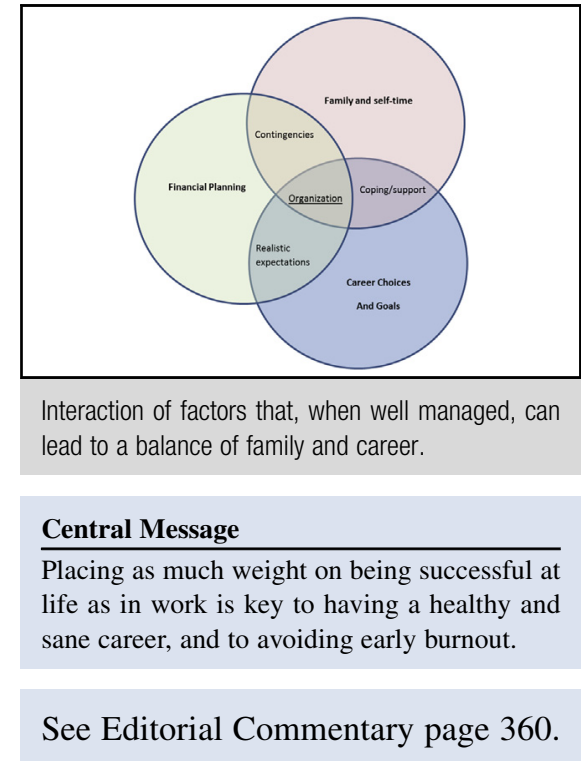

met criteria for burnout, and a 30\% rate of surgeons with a mental quality of life score more than a half standard deviation below the population norm. Being young, newer to practice, and less experienced can understandably increase the amount of work-related stress. Younger surgeons were additionally more likely to have a working domestic partner (typically a physician), which seemed to exacerbate depressive symptoms and create more conflicts at home. The eventual implications of this relationship dynamic can be lower work satisfaction and even the belief that raising children can slow career advancement. ${ }^{5}$ Moreover, compared with 13 other surgical specialties, cardiothoracic surgeons reported the second-highest rate of suicidal ideation $(7.3 \%)$, and the highest number of work hours in the operating room. ${ }^{6}$

So how can we avoid burnout and achieve work-life balance? How can we remain dedicated to patient care without feeling overworked and emotionally and physically depleted? Is it really possible to attain both professional and personal fulfillment in the field of cardiothoracic surgery?

To answer these questions, we have to acknowledge first that the definition of work-life balance is personal and will vary on an individual basis. For some, balance could be as simple as being able to go on an outdoor weekend trip with the family; for others, it means being able to participate in humanitarian missions abroad. Therefore, defining this balance requires some introspection and self-awareness about our goals and priorities, which will enable us to 
make deliberate decisions and realize our power to change course at any time.

In addition, achieving this balance requires choosing the right career path, with a focus on what is most important for us, whether it is teaching students and residents, having protected academic time for publications or grants, or placing more emphasis on clinical work. Having understanding and supportive partners and mentors can substantially alleviate our stress as well. When interviewing for a job, we are mostly focused on professional parameters to help us make the best decision. It may be wise to place some weight on other factors, such as coverage overnight and on the weekends, amount of allowed personal time, and whether sick or paternity leave is available. Surely, these parameters are subject to budgetary restraints and may be difficult to attain or negotiate, but keeping them in perspective is important in making a decision that ultimately involves our family too. Some of us may even prefer to be remunerated less, if doing so would mean, for example, more midlevel assistance and a potentially better quality of work, which will eventually translate into better quality of life. Performing all types of cardiothoracic operations in our field is no longer realistic and can become onerous, making us feel stretched too thin. Focusing on specific clinical aspects at work and developing expertise in a defined field may actually be less stressful, more productive, and more rewarding. One must take into account future expectations and plans; eg, do you want to have a predominant transplantation practice at age 58 years?

The balance of work with personal life starts with setting aside time for family and self, overlapped by career path decisions. Organization is the key to durable balance, with clear expectations of goals, responsibilities, and recreation (Figure 1).

\section{GOALS}

Set midterm and longterm career goals and plan a clear path to achieve them. Put your plans on paper and review them often, making sure they are current. Life is dynamic, and adapting to a changing work and family environment is very important. Many surgeons, especially those interested in an academic career, will find it necessary to move their family. This can be very stressful for everyone involved, rendering a family discussion mandatory for good career planning.

Go back to your personal statement when you applied to general surgery, and compare it with the one you wrote when you applied for cardiothoracic surgery: Surely, hints and clues about your aspirations are there. Some professional decisions (eg, full-time participation in editorial boards or professional association committee leadership positions) are more taxing with young children, and one has to contemplate the time commitment required to satisfy these activities. On a personal level, create realistic expectations

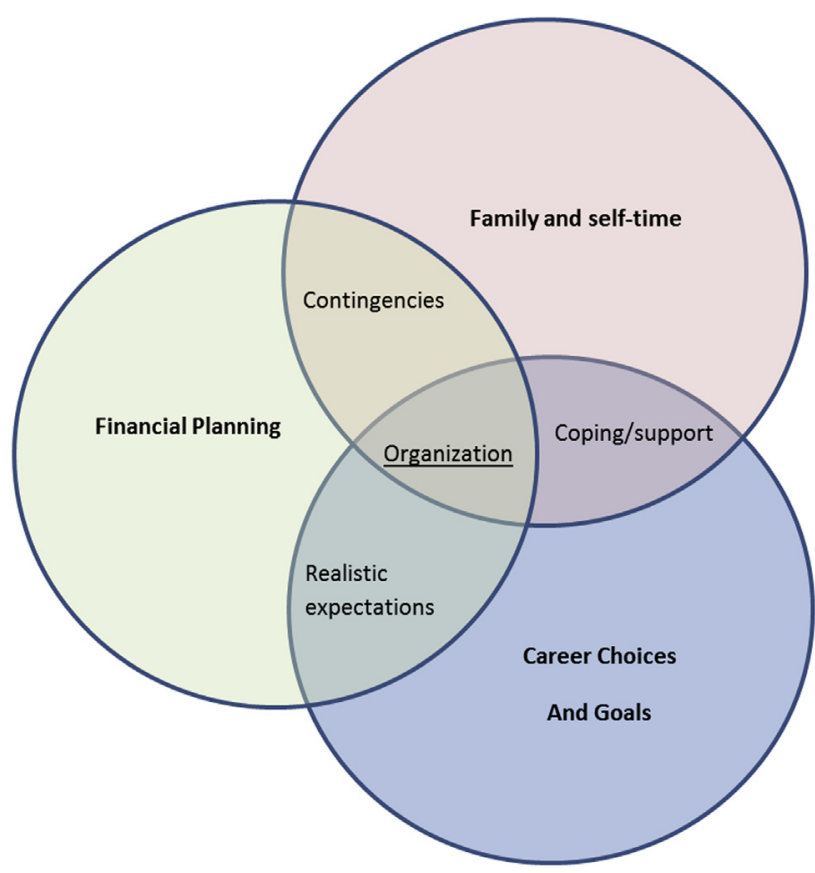

FIGURE 1. Interaction of factors that, when well managed, can lead to a balance of family and career.

in regard to which family events you will attend, as it is unlikely that one can participate in all school functions, recitals, plays, and sports tournaments. Simple things, such as coordinating your call schedule with your partner's at work, can help tremendously to protect family time. Even better, organizing a picnic or any other family outing with our colleagues and residents will help create a solid bond and add a human touch to our daily job.

\section{COPING/SUPPORT}

Cardiothoracic surgery is a high-acuity specialty, in which morbidity and mortality can occur even in the perfect setting. Acquiring and mastering a mechanism to cope with the loss brought on by such adverse outcomes is important, notwithstanding the intellectual understanding of the circumstances that led to the outcome. Coping mechanisms can be found in meditation, religion, family or friend support, and when warranted, counseling. Without emotionally processing losses, one cannot fully learn from the event and move forward. Celebrating small and large victories at home and work is very important. Having caretaker contingency plans when one has young children will allow for successful navigation through adversities.

\section{PROTECTING FAMILY AND SELF TIME}

Setting aside time to spend with spouse and children is perhaps the most important aspect of a balanced career-personal life. Protecting time with family and self may prove to be easier than one thinks. Organization is the key. 
Coordinate your call schedule with your spouse and children, separating time for important events. Sharing with your spouse is the cornerstone of balanced life. Educating a nonphysician partner without overwhelming them is helpful to avoid work-home conflicts. Talking about everyday events, good or bad, is important, but be sensitive not to bring home tragedy and disillusion daily. Do not come home carrying the burden of a bad, busy, or tragic day. Leave work-related activities at work as much as you can, but more importantly, avoid not getting home in time to share with family, even if it means typing clinic notes late at night at home. It is better for your children to perceive you as a busy, loving parent than as an absent one.

Participate in your children's lives, know their friends, and know their wins and hardships. Try to take them to school or pick them up at least once a week. They will know you are present and will share with you. Whenever possible, take your family with you to meetings, especially in tourist-friendly places, and reserve exclusive time at the beginning or end just to share with your loved ones. In fact, many family-friendly conference venues (eg, general thoracic surgical club) aim to provide relevant scientific material and allow family time in the same setting. Plan ahead to be able to take time off for special events, such as birthdays and anniversaries. Attend family and friend reunions as much as possible; doing so will energize you and give you perspective. Maintaining a sense of "normalcy" or "sanity" is reinforced by interacting with family and friends outside of medicine.

Another crucial component of work-life balance is to promote personal wellness strategies. These include simple activities, such as exercising, seeking preventive medical care, and finding hobbies that provide mental solace, such as gardening, reading, and hiking. Cultivating one's hobbies is important to maintain a healthy sense of self. Some of these hobbies, such as photography, can be shared with the family, and they allow spending time outdoors and traveling together to find great images. Be introspective, humble, and courageous, all attributes that allowed you to become a cardiothoracic surgeon, and work hard on selfimprovement every day.

\section{FINANCIAL PLANNING}

Cardiothoracic surgeons are at the epitome of performance under pressure, but this does not translate into good long-term planning. Many of us do not possess good financial and planning skills; therefore setting aside time to discuss mid- and long-term goals with your spouse and/or a financial planner is important. In fact, cardiothoracic surgeons have reported a steady increase in education-related debt over the years. ${ }^{7}$ Achieving financial peace of mind will allow a smoother navigation through difficult life events. Seeing a talented surgeon sacrifice family time and treasure in the early years of his/her career only to face economic difficulties upon retirement is tragic.

\section{CONCLUSIONS}

Achieving a work-life balance is a challenging task and is always in flux. Many of us have type-A personalities and are task driven. But here may lie the remedy: Realizing that there is life outside of work and placing as much weight on being successful in life as in work can be the driving force behind achieving this balance. In addition, we owe it to our residents, fellows-in-training, and junior partners to be role models in achieving this balance.

\section{Primum Non Nocere}

The Hippocratic Oath we all took in medical school is obviously directed toward patients, who remain at the core of what we do every day. However, with the pressure of modern medicine and modern life, it may be wise and unselfish to step back a little and consider applying this pledge to ourselves, surgeons and physicians alike. After all, our patients need us to be not only competent, but also healthy, lucid, and compassionate.

\section{References}

1. Williams TE, Sun B, Ross P, Thomas AM. A formidable task: Population analysis predicts a deficit of 2000 cardiothoracic surgeons by 2030. J Thorac Cardiovasc Surg. 2010;139:835-40.

2. Shanafelt TD, Bradley KA, Wipf JE, Back AL. Burnout and self-reported patient care in an internal medicine residency program. Ann Intern Med. 2002;136: 358-67.

3. Shanafelt TD, Balch CM, Bechamps G, Russell T, Dyrbye L, Satele D, et al Burnout and medical errors among American surgeons. Ann Surg. 2010;251: 995-1000.

4. Shanafelt TD, Balch CM, Bechamps GJ, Russell T, Dyrbye L, Satele D, et al Burnout and career satisfaction among American surgeons. Ann Surg. 2009;250: 463-71.

5. Dyrbye LN, Shanafelt TD, Balch CM, Satele D, Freischlag J. Physicians married or partnered to physicians: a comparative study in the American College of Surgeons. J Am Coll Surg. 2010;211:663-71.

6. Balch CM, Shanafelt TD, Sloan JA, Satele DV, Freischlag JA. Distress and career satisfaction among 14 surgical specialties, comparing academic and private practice settings. Ann Surg. 2011;254:558-68.

7. Sarkaria IS, Carr SR, MacIver RH, Whitson BA, Joyce DL, Stulak J, et al. The 2010 Thoracic Surgery Residents Association workforce survey report: a view from the trenches. Ann Thorac Surg. 2011;92:2062-70. 